\title{
Methods of biological maceration in the preparation of bat skulls: benefits and limitations
}

\author{
Marcione Brito de Oliveira ${ }^{1,2,3}$ \\ 1 Universidade Federal do Rio de Janeiro (UFRJ), Museu Nacional, Departamento de Vertebrados, Mastozoologia. Rio de Janeiro, RJ, Brasil. \\ ${ }^{2}$ Universidade Federal Rural do Rio de Janeiro (UFRRJ), Instituto de Biologia, Laboratório de Mastozoologia. Seropédica, RJ, Brasil. \\ 3 ORCID: 0000-0003-1628-3458. E-mail: oliveira01marcione@gmail.com
}

\begin{abstract}
Osteologic collections are used as an aid to scientific and teaching activities, to provide information on specific vertebrate characteristics, such as body support, posture, mode of locomotion, feeding habits and ecological niche. Known techniques for cleaning entire skeletons or mammalian skulls vary according to the destination of the material, the objective of the study, the taxonomic group, and the size of the specimen. The objective of this study was to test three different methods of maceration for cleaning bat skulls (traditional biological maceration, controlled biological maceration using Dermestes maculatus and controlled biological maceration using necrophagous fly larvae). The methods were carried out during five consecutive months, and the minimum and maximum times taken by each method were recorded and documented. Cleaning by fly larvae was the least costly method; the whole process was carried out during the preparation of the osteologic material. The flies ovulated directly on the pieces and the time spent was relatively short. Cleaning by dermestid larvae also resulted in clean parts in a short period, however, its culture needs specific maintenance conditions, since the size of the colony oscillates according to environmental temperature.
\end{abstract}

Key-Words. Osteologic material; Cleaning; Dermestides; Fly larvae; Chiroptera.

\section{INTRODUCTION}

The main purpose of scientific collections is to store and catalogue preserved voucher specimens (both entire organisms or body parts) for the purpose of teaching, decoration and scientific research, in different fields of knowledge (Papavero, 1994; Sullivan, 1999; Sullivan \& Romney, 1999; Auricchio \& Salomão, 2002; Nunes \& Perônico, 2003; Zaher \& Young, 2003; Silveira \& Oliveira, 2008; Simmons \& Voss, 2009). Collections may hold all sets of individual morphological, gender or age-related variations that are normally found in nature (Hensel, 1872; Avila-Pires, 2011). Systematic collections of mammals, in particular, are an indispensable and nonrenewable resource, and have provided invaluable data, for instance, on evaluating the extent of environmental impacts in certain localities, as they present information on species previously occurring in the area, as well as providing recent wildlife inventories and subsidies for studies on geographical distribution, phylogeny, speciation, biogeography, taxonomy, among others (Genoways et al., 1987).

Knowledge on the preparation and preservation techniques of biological material that is deposited in collections is essential to its proper management (Hafner et al., 1984; Santos \& Valverde, 2006). There are several methods and protocols used for the preparation and preserva- tion of specimens. Improvement on these methods for the rational use and better preservation of the material, as well as the organization of the necessary physical space and adequate storage of the material, has always been of great concern for collectors and curators of collections (Rose et al., 1995; Nunes \& Perônico, 2003; Beaman et al., 2004; Simmons \& Voss, 2009).

Since Hensel (1872), when variations in cranial and dental characteristics started to be considered essential criteria for taxonomic identification in several studies, the preservation of clean skulls has become increasingly necessary. This is especially important for mammals, for which the analysis of cranial characteristics is fundamental for species identification and for verification of age and sexual variations (Sullivan, 1999; Sullivan \& Romney, 1999; Oliveira et al., 2014). Furthermore, teeth morphology is also useful when identifying eating habits of an individual and its position within the food chain, defining feeding habit (Sullivan, 1999; Sullivan \& Romney, 1999; Genoways et al., 1987).

Skeletons and skulls must be properly prepared, so that quality specimens can be obtained, avoiding damaged or modified bones, which may impair or influence the morphological analysis of the original characters and the resulting taxonomic identification (Silveira \& Oliveira, 2008). Currently, several cleaning techniques are known, including boiling the material with manual clean- 
Table 1. Phases of the three cleaning processes tested. Biological maceration (with cold water), Cleaning by fly larvae and by dermestid larvae.

\begin{tabular}{llll}
\hline \multicolumn{1}{c}{ Stage } & \multicolumn{1}{c}{ Biological Maceration } & \multicolumn{1}{c}{ Fly Larves } & Dermestids \\
\hline Hydration with Water & Submerged throughout the process & Submerged between 3 to 5 hours & Not needed \\
Review & Every 4 days & Every 2 days & Every 2 days \\
Maintenance & Change the water every 7 days & Keep the cotton damp around skull & Replace larvae when needed \\
Duration & Undetermined & Between 14 days to 4 weeks & Between 10 days to 4 weeks \\
\hline
\end{tabular}

ing, biological maceration (with bacteria), application of chemical substances, and the use of larvae of various species of arthropods (Sullivan, 1999; Auricchio \& Salomão, 2002). The advantages and disadvantages of these methods, their operation and maintenance costs should be carefully considered by the curators in the management of the collections (Rose et al., 1995; Genoways et al., 1987).

Bats are among the smallest mammals, and some methods can damage the material or do not yield satisfactory results because they were developed for the cleaning of complete skeletons and/or larger skulls. Our goal here was to test and compare the methods used in traditional and controlled biological maceration with the use of dermestid and fly larvae and to verify which is most suitable for the cleaning and preparation of bat skulls.

\section{MATERIAL AND METHODS}

The methods tested for cleaning the skulls were: (1) Maceration with fly larvae, (2) Maceration with dermestid larvae, and (3) Biological maceration with cold water (Table 1). The tests were carried out at the Sector of Mammalogy, Department of Vertebrates of the National Museum, Rio de Janeiro (MN-UFRJ), between march and July of 2015. During this period, the temperature for the region of Rio de Janeiro ranged from a minimum of $17^{\circ} \mathrm{C}$ to a maximum of $36^{\circ} \mathrm{C}$, with an average of $21^{\circ} \mathrm{C}$ (INMET, 2015), and no environmental temperature control was done. Sixty-one bat skulls belonging to 22 species (see Appendix 1), with total skull length ranging from $11.57 \mathrm{~mm}$ to $31.3 \mathrm{~mm}$, were submitted to the three meth-

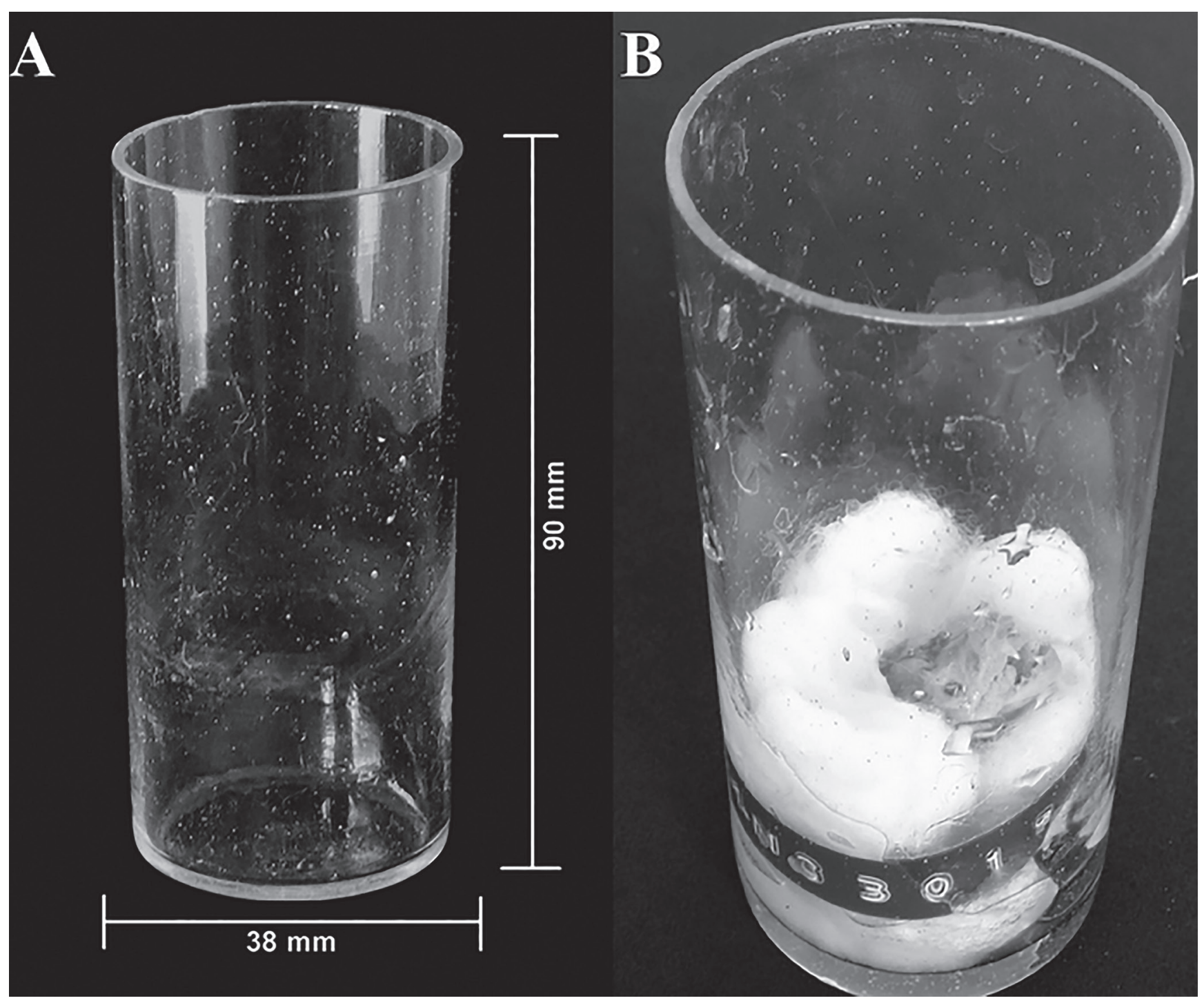

Figure 1. (A) Glass vessel ( $90 \mathrm{~mm}$ height and $38 \mathrm{~mm}$ diameter) used to hold the skulls during the experiment. (B) Container with a Carollia brevicauda (MN 83019 ) skull. 
ods of maceration, including for each method a smaller skull (mean of $12.96 \mathrm{~mm}$; e.g., Myotis sp.), one of medium size (mean of $21.88 \mathrm{~mm}$; e.g., Sturnira lilium) and a larger one (mean of $28.55 \mathrm{~mm}$; e.g., Artibeus planirostris). We recorded the minimum and maximum time of each process and the integrity of the different sized skulls. The skulls were previously removed from specimens (which had been preserved in $70 \%$ alcohol after fixation with $10 \%$ formalin) from the Mammalian Collection of the Department of Vertebrates at the National Museum, Rio de Janeiro.

The skulls of specimens were extracted directly through the mouth opening, via folding of the skin, as recommended by Nunes \& Perônico (2003) and Simmons $\&$ Voss (2009).

\section{Maceration with necrophagous fly larvae (Insecta - Diptera) - adapted for cleaning bat skulls}

The materials used for the experiment were water, hydrophilic cotton, a glass container large enough to accommodate the skull and cotton, with enough space between the skull and the edge of the glass, to facilitate handling (Figs. 1A and B), and a rectangular glass tank (between 32 to 60 liters in size) to store the containers with the skulls. All skulls were individually marked with a vinyl tape label, containing collection registration number, prepared with a handheld label maker.

Was used 39 skulls in this process, being 11 small, 25 medium and three large. Small skulls were previously submerged in water for two hours, while larger skulls were submerged for three hours for hydration. All skulls were then removed from water and wrapped in wet cotton (Fig. 2A), leaving an opening in the upper part to allow the flies to deposit their eggs. This step can be repeated after four days, if no larvae are seen. The material should be kept in a well-ventilated place and accessible to flies, away from the collection. After 2 to 6 days, when larvae are observed, the rostrum of the skull is positioned towards the opening of the container, away from the wet cotton (Fig. 2B). A piece of dry cotton should be placed between the mandible and the maxilla whenever necessary, and changed at every checking, to prevent the teeth of the smaller skulls from falling out due to prolonged exposure to moisture. The containers were kept inside an open aquarium, since fly larvae do not move between the containers as do the dermestid larvae. Checking was done every two days. The cotton around the skull was kept constantly moist, to prevent the skulls from drying out.

After the third molt, the larvae bury themselves deep in the matter on which they feed. Their skins darken and start to harden to enter the pupa stage and must be prevented from reaching adulthood. At the end of the process, the cotton used was submerged in a sodium hypochlorite solution $(\mathrm{NaClO})$ for half an hour and discarded shortly afterwards, in order to kill the remaining larvae or pupae. Skulls that show darkening can be bleached in $3 \%$ hydrogen peroxide solution $\left(\mathrm{H}_{2} \mathrm{O}_{2}\right)$ for 30 minutes (Sullivan \& Romney, 1999).

\section{Maceration with dermestids}

Was used Dermestes maculatus (Coleoptera, Dermestidae) (Auricchio \& Salomão, 2002) on twelve skulls in this test, being five small, three medium and four large. Each dried skull was wrapped in cotton and packed in individual glass containers. All containers were placed inside the glass tank filled with cotton, so that the adult beetles and larvae could move between the containers. The tank was covered with a cloth screen and kept in a well-sealed room, with internal ventilation. Verification of the cleaning process occurred every two days. Additional larvae were added to the containers when necessary, because of death of individuals during the process. In this process no water was used.

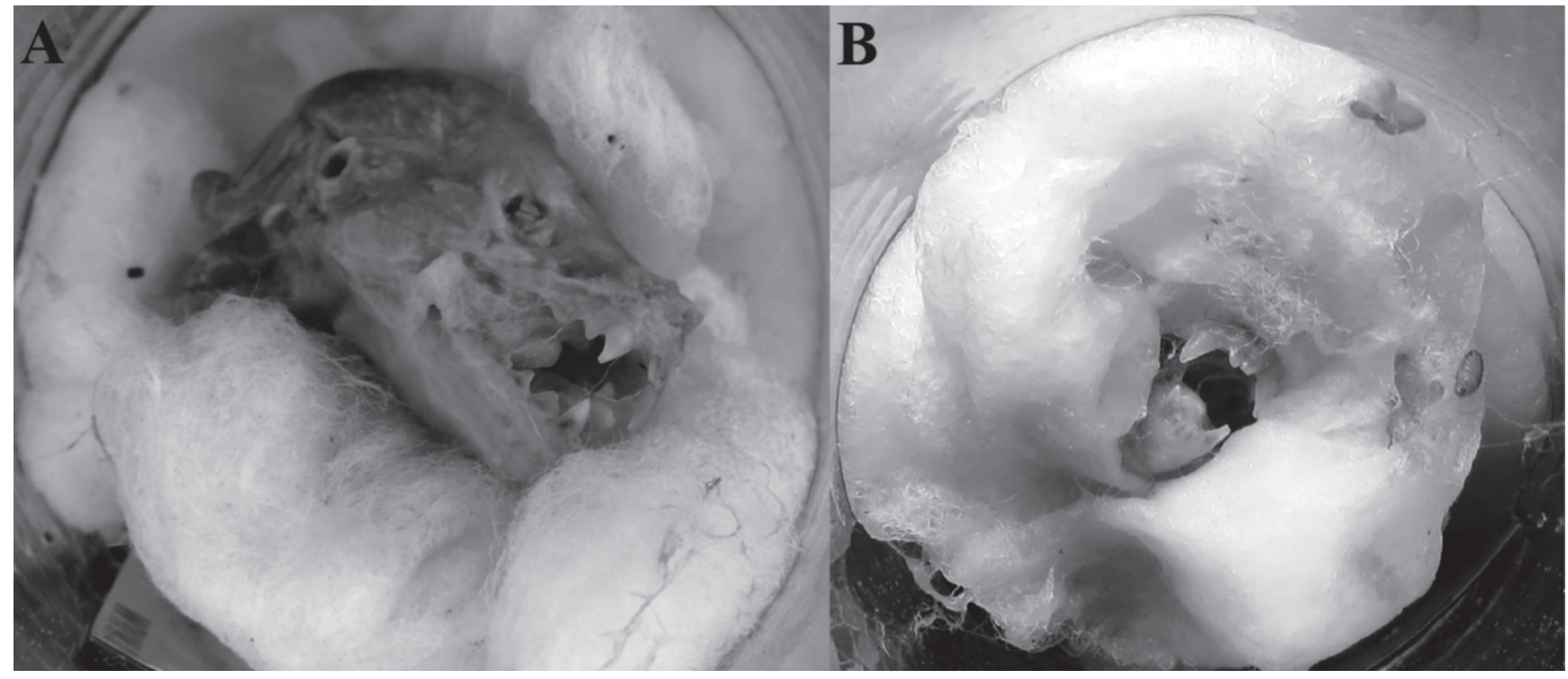

Figure 2. (A) Carollia brevicauda skull (MN 83019) placed on wet cotton in the first days. (B) Same skull after oviposition. 


\section{Biological maceration with cold water}

Ten skulls were used in biological maceration, being two small, seven medium and one large. The skulls were placed in a container filled with cold water and set away from direct sunlight (Auricchio \& Salomão, 2002; Nunes \& Perônico, 2003). The material was checked every four days, and water was changed weekly to prevent darkening and deterioration of the skull. Cotton was not used in this process.

\section{End of each cleaning process}

The clean skulls are washed in running water to remove coleopteran and Dipteran larvae. With the aid of surgical forceps, any remaining brain fragments inside the cranium are removed through the foramen magnum, and a thorough check is conducted to remove larvae which may remain inside the skull. An alternative is to immerse the pieces (skulls) in alcohol for one or two hours. This step helps kill larvae and dry the skull faster. The skulls were then allowed to dry in a clean vessel at room temperature for five days. Subsequently, the dried skulls were packed in an appropriate container, receive a final label with a register number and are deposited in the Collection of the National Museum.

\section{RESULTS}

The cleaning of the skulls was considered acceptable for two of the controlled maceration methods, with dermestid larvae and the necrophagous fly larvae. Of the 22 species of bats that were cleaned by both methods, seven small skulls were cleaned in between 10 and 14 days, while the medium to larger skulls were cleaned between 14 and 28 days (Table 2). Total cleaning time was not satisfactory due to adversities during the processes.

\section{Maceration with necrophagous fly larvae}

The first phase of hydration, where the skull is submerged in water, had to be repeated for some of them,
Table 2. Number of days spent in cleaning skulls by controlled maceration with larvae of dermestids and fly larvae for 22 species of bats. $\mathrm{N}=$ number of individuals; Average skull length (in millimeters).

\begin{tabular}{llcll}
\hline \multicolumn{1}{c}{ Species } & N & Average skull length & Size & Total days \\
\hline Eptesicus diminutus & 2 & 14,36 & & \\
Eptesicus furinalis & 3 & 14,43 & & \\
Molossops temminckii & 3 & 14,38 & & \\
Myotis nigricans & 4 & 13,32 & Small & 10 to 14 \\
Myotis riparius & 2 & 13,89 & & \\
Myotis simus & 2 & 13,92 & & \\
Rhynchonycteris naso & 2 & 11,86 & & \\
\hline Chiroderma villosum & 3 & 24,46 & & \\
Glossophaga soricina & 10 & 20,44 & & \\
Lophostoma brasiliense & 1 & 20,32 & & \\
Mimon crenulatum & 2 & 21,5 & & \\
Molossus molossus & 1 & 17,69 & & \\
Molossus pretiosus & 4 & 20,75 & Medium & 14028 \\
Platyrrhinus incarum & 2 & 21,61 & & \\
Platyrrhinus lineatus & 3 & 24,2 & & \\
Sturnira lilium & 7 & 22,9 & & \\
Sturnira tildae & 2 & 24,05 & & \\
\hline Artibeus lituratus & 1 & 31,3 & & \\
Artibeus planirostris & 4 & 28,07 & & \\
Lophostoma silvicolum & 1 & 26,27 & & \\
Phyllostomus discolor & 1 & 29,16 & & \\
Trachops cirrhosus & 1 & 29,45 & & \\
\hline
\end{tabular}

to better remove the formalin (10\%) used as fixative. This fixative prevents the larvae from settling on the carcass, making egg laying difficult for the flies. The first check, two days after the skulls were exposed to the flies, revealed the presence of small larvae (indicating an initial larval stage) primarily removing the inner part of the skull. On the fourth check (eighth day), several different sized larvae (Figs. 3A, B and C) were observed, both inside and outside the skull. The larval population size was considered relatively constant after eight days, the variation being mainly in the size of the larvae that grew during the process.

A small skull and a medium showed fragility of the teeth, some of which fell during the cleaning process. The rostrum was then repositioned towards the opening of the cotton, with minimal contact with wet cotton. The mandible, especially of skulls of the smaller genera (e.g., Myotis sp.), may look very fragile after maceration, due to


Figure 3. (A) Sturnira lilium skull (MN 82282) hydrated for the cleaning process by fly larvae. (B) The same skull on the eighth day of contact with fly larvae. (C) After 21 days of maceration. 




Figure 4. Skull of Sturnira lilium (MN 82282), prepared by the controlled maceration method with fly larvae.

long exposure to moisture. Greater care is needed when washing the mandible on these. At the end of the process, clean skulls were obtained, with little or no damage, some pieces showing a slight darkening (Fig. 4).

\section{Maceration with dermestids}

The use of dermestids presented satisfactory results and there was little or no damage to the skulls. However, it was difficult to keep the colony in adequate sizes. On days when ambient temperature was lower, the colonies took longer to reproduce and the population declined dramatically, making the cleaning process more time-consuming. The opposite was observed on days with higher temperatures. The ambient temperature during the experiment was verified on the INMET website. During the process, the larvae consumed bone parts of some skulls, even if they were not completely clean. The cleaning lasted from one week and three days to four weeks (10 and 28 days, respectively), depending on the total size of the skull and the size of the colony (Table 2).

\section{Biological maceration with cold water}

This method did not show good results for bat skulls. The skulls began to show evidence of rotting after eight days of initiating the process. All showed signs of bone wear and some parts became very soft. Some parts were not cleaned during the process. The waste was removed manually, then the skulls were washed and left to dry for five days.

\section{DISCUSSION}

Dermestid and fly larvae maceration techniques presented advantages and disadvantages when applied. Both were considered feasible and more practical, when compared to other techniques, such as biological maceration with cold water or with chemicals, having shown little or no damage to the skulls (Auricchio \& Salomão, 2002; Silveira \& Oliveira, 2008), because of their small size, bat skulls need constant monitoring during maceration processes.

The limitations of controlled maceration with dermestids are related to the need to maintain the colony at a suitable size and to control temperature oscillations, which is a determinant factor for the efficiency and especially for the duration of the process (Sullivan \& Romney, 1999; Rodrigues et al., 2012). According to Köb (2006), the ideal temperature to maintain a colony of dermestids is around $25^{\circ} \mathrm{C}$. In the present study, temperature oscillations could not be controlled in the space reserved to maintain the colonies, making this method more difficult. This limitation was one of the reasons why there were fewer clean skulls with this method than those cleaned by controlled maceration with fly larvae. Not all institutions have adequate physical space or temperature control to maintain a dermestid colony. In addition, these colonies cannot be kept close to scientific collections (Auricchio \& Salomão, 2002). Therefore, their use can be quite effective, but knowledge about alternative methods is also necessary.

The present study is the first to show satisfactory results for cleaning bat skulls with controlled maceration by fly larvae, and no previous description of this method is found for bats in the literature. The main families of Diptera that usually oviposit in mammal carcasses are Calliphoridae, Sarcophagidae, Muscidae and Fanniidae (Marcolino, 2014). Their larvae can be maintained with humidity control and exposure time, with no temperature restriction or control necessary, though the process must still be carried out in a well-ventilated location, away from zoological collections (Auricchio \& Salomão, 2002; Oliveira-Costa et al., 2011). Considering the relatively low costs, the easiness of obtaining larvae, and the short cleaning period, the method of controlled maceration by fly larvae becomes a viable alternative for the preparation of bat skulls. The disadvantages found in using the fly larvae cleaning process are usually the strong smell and darkening of the skeleton (Auricchio \& Salomão, 2002). However, due to the smaller size of the bat skulls, no strong smell was detected during the process. Some skulls presented a slight darkening after maceration, which was easily reverted after bleaching with $\mathrm{H}_{2} \mathrm{O}_{2}$ solution at $3 \%$ from 10 to 30 minutes. No part 
presented bone wear with this procedure, however, a greater care with the jaw is necessary because of the possibility of losing the teeth when exposed to long periods of humidity.

Was used a minimum of 10 skulls in each experiment using controlled maceration by fly larvae. Smaller number of skulls may be less attractive to flies, thus affecting cleaning time, due to the smaller bulk size of the skulls. However, containers with raw hydrated meat may be kept along with the skulls to promote oviposition by the flies. Larvae developed at this stage should be used to clean the skulls.

The process of biological maceration with cold water did not produce a satisfactory result, and we do not recommend it for cleaning bat skulls of any size, due to their fragility. Studies using biological maceration have shown diverse results, being satisfactory in some cases, with a great variety of taxonomic groups and sizes (Nunes \& Perônico, 2003) or unsatisfactory in others, due to a longer cleaning time and to loss of teeth (Sullivan \& Romney, 1999).

\section{CONCLUSIONS}

Because of their small size, bat skulls need constant monitoring during maceration processes. When using fly larvae, a relatively short time of cleaning was observed, without the need of previous colony formation, with the added advantage of raising the larvae in the skulls themselves, of being carried out in a ventilated environment, away from the collection, and without the need of damaging chemicals during the process. The method of controlled maceration with dermestids also required relatively short time and did little damage to the skulls, but the need for appropriate conditions for colony establishment and maintenance may be a limiting factor for some institutions, for the use of this method

\section{ACKNOWLEDGEMENTS}

I thank Dr. Luiz Flamarion B. de Oliveira and Dr. João A. de Oliveira for allowing and assisting when necessary during the process of cleaning the skulls at the National Museum of Rio de Janeiro. Special thanks to Dr. Daniela Dias, MSc. Carlos A. Sousa and Sergio Moreira, three friends and professionals who helped with their guidelines and revisions during the construction of the manuscript. Finally, I thank Danielle Crawshaw and Nathalie Heinzelmann for their precious revisions of English.

\section{REFERENCES}

Auricchio, P. \& Salomão, M.G. 2002. Técnicas de coleta e preparação de vertebrados para fins didáticos e científicos. Arujá, SP, 0 Instituto Pau Brasil de História Natural.
Avila-Pires, F.D. 2011. Mudanças nas práticas de coleta e estudo dos mamíferos a partir do século XVIII. Filosofia e História da Biologia, 6(2): 211-226.

Beaman, R.; Wieczorek J. \& Blum, S. 2004. Determining space from place for natural history collections. D-lib Magazine, 10(5): 9.

Genoways, H.H.; Jones C. \& Rossolimo, 0.L. 1987. Mammal Collection Management. Lubbock, Tx, Texas Tech University Press.

Hafner, D.J.; Hafner, J.C. \& Hafner, M.S. 1984. Skin-Plus-Skeleton Preparation as the Standard Mammalian Museum: Specimen. Curator The Museum Journal, 27(2): 141-145.

Hensel, R.F. 1872. Beiträge zur Kenntniss der Säugethiere Süd-Brasiliens. Berlin, Königlichen Akademie der Wissenschaften. 130p.

INMET - Instituto Nacional de Meteorologia. 2015. Ministério da Agricultura, Pecuária e Abastecimento. Rio de Janeiro, temperatura. Available at: $\underline{w w w}$. inmet.gov.br/portal/index.php?r=tempo/graficos. Access in: 17/01/2016.

Köb, E.L. 2006. Ciclo de vida de Dermestes maculatus DeGeer, 1774 (Coleoptera, Dermestidae). Curitiba, Universidade Federal do Paraná. (Monografia).

Marcolino, Z.L. 2014. Dermestes maculatus DeGeer (Coleoptera, Dermestidae) associado a carcaças expostas de Sus scrofa L. em uma área situada em microrregião do sertão paraibano. Campina Grande, Universidade Estadual da Paraíba. (Monografia)

Nunes, D.P. \& Perônico, C. 2003. Implantação e proposta de informatização da coleção osteológica de referência do laboratório de zoologia e anatomia comparada do Unileste, MG. Available at: www.unilestemg. br/revistaonline/volumes/02/downloads/artigo 19.pdf. Access in: 30/06/2015

Oliveira, J.A.D.; Bonvicino C.R. \& D'Andrea, P.S. 2014. Técnicas de preparação de mamíferos para estudos epidemiológicos: taxidermia, fixação e registro de informações. In: Lemos, E.R.S. \& D'Andrea, P.S. (Eds.). Trabalho de campo com animais: procedimentos, riscos e biossegurança. Rio de janeiro, FIOCRUZ. p. 127-135.

Oliveira-Costa, J.; Dias G.S. \& Meloni, E. 2011. Metodologia de coleta para pesquisas experimentais. In: Oliveira-Costa, J. Entomologia Forense: quando os insetos são vestígios. 3.ed. Campinas, SP, Millennium Editora. p. 413-425.

Papavero, N. 1994. Fundamentos práticos de taxonomia zoológica. São Paulo, UNESP.

Rodrigues, A.B.F.; Lima, A.C.Q.; Nogueira, C.H.O.; Bogossian P.M. \& Rocha, V.N. 2012. Utilização de coleópteros na preparação de material osteológico. PUBVET, Londrina, 6: 1277-1282.

Rose, C.L.; Hawks C.A. \& Genoways, H.H. 1995. Storage of natural history collections: A preventive conservation approach. New York, Society for the Preservation of Natural History Collections.

Santos, I.B. \& Valverde, M.C.C. 2006. Coleções osteológicas: uma contribuição ao ensino da Zoologia na Universidade Estadual de Feira de Santana, Bahia. Sitientibus Série Ciências Biológicas, 6(2): 162-164.

Silveira, M.J. \& Oliveira, E.F. 2008. A importância das coleções osteológicas para 0 estudo da biodiversidade. SaBios - Revista de Saúde e Biologia, 3: 1-4.

Simmons, N.B. \& Voss, R.S. 2009. Collection, preparation, and fixation of bat specimens and tissues. In: Kunz, T.H. \& Parsons, S. (Eds.). Ecological and behavioral methods for the study of bats. Johns Hopkins University Press, Baltimore, Maryland, p. 849-867.

Sullivan, L.M. 1999. Wildlife Skull Activities. The University of Arizona Cooperative Extension AZ1145. Available at: https://extension.arizona. edu/pubs. Access in: 09/07/2015.

Sullivan, L.M. \& Romney, C.P. 1999. Cleaning and Preserving Animal Skulls. The University of Arizona Cooperative Extension AZ1144. Available at: https://extension.arizona.edu/pubs. Access in: 09/07/2015.

Zaher, H. \& Young, P.S. 2003. As coleções zoológicas brasileiras: panorama e desafios. Ciência e Cultura, 55(3): 24-26. 